\title{
REAÇÕES FAMILIARES DIANTE DA CRIANÇA EM SITUAÇÃO DE DEFICIÊNCIA ${ }^{1}$
}

\author{
MARQUES, Luciana Pacheco (Brasil, Minas Gerais, Juiz de Fora) ${ }^{1{ }^{*}}$ \\ ${ }^{1}$ Universidade Federal de Juiz de Fora \\ ORCID ID: https://orcid.org/0000-0003-2430-831X
}

\begin{abstract}
RESUMO
Este estudo teve por finalidade apreender a complexidade vivida pela família da criança em situação de deficiência a partir do seu próprio ponto de vista. Foram realizadas entrevistas na linha não diretiva e de ajuda com seis mães de crianças em situação de deficiência, as quais descreveram suas histórias de vida. A partir dos relatos, construiu-se a discussão sobre diferentes tópicos, tratando-se especificamente neste texto das reações familiares diante do nascimento de uma criança em situação de deficiência na família. Negar, rejeitar, buscar um culpado para a situação, refugiar-se no seu sofrimento são algumas reações perfeitamente possíveis nos pais de crianças em situação de deficiência. Todavia, a busca do equilíbrio e o encaminhamento das questões afetas ao ser desviante tendem a surgir com o tempo e o filho em situação de deficiência é quase sempre incorporado à dinâmica familiar.
\end{abstract}

\section{PALAVRAS-CHAVE}

Família. Deficiência. História de vida.

\section{FAMILY REACTIONS BEFORE THE CHILD IN THE SITUATION OF DISABILITY}

\begin{abstract}
The purpose of this study was to understand the complexity experienced by the family of children with disabilities from their own point of view. Non-directive and assistance interviews were conducted with six mothers of children with disabilities who described their life histories. From the reports, the discussion on different topics was constructed and in this text we will deal specifically with the family reactions to the birth of a child with a disability in the family. To deny, to reject, to find a culprit for the situation, to take refuge in their suffering are some perfectly possible reactions in the parents of children with disabilities. However, the search for balance and the referral of the issues of being deviant tend to arise over time and the child in a disability situation is almost always incorporated into the family dynamics.
\end{abstract}

\section{KEYWORDS}

Family. Deficiency. Life's history.

1 Artigo produzido a partir da dissertação de mestrado de Marques (1992).

Educação \& Formação, Fortaleza, v. 4, n. 12, p. 67-81 set./out. 2019

DOI: https://doi.org/10.25053/redufor.v4i12.912

http://seer.uece.br/redufor 


\title{
REACCIONES FAMILIARES DIANTE DEL NIÑO EN SITUACIÓN DE DEFICIENCIA
}

\begin{abstract}
RESUMEN
Este estudio tuvo por finalidad aprehender la complejidad vivida por la familia del niño en situación de discapacidad desde su propio punto de vista. Se realizaron entrevistas en la línea no directiva y de ayuda con seis madres de niños en situación de discapacidad, que describieron sus historias de vida. A partir de los relatos, se construyó la discusión sobre diferentes tópicos. En este texto, se tratará específicamente de las reacciones familiares ante el nacimiento de un niño en situación de deficiencia en la familia. Negar, rechazar, buscar a un culpable para la situación, refugiarse en su sufrimiento son algunas reacciones perfectamente posibles en los padres de niños en situación de discapacidad. Sin embargo, la búsqueda del equilibrio y la resolución de problemas que afectan la desviación tienden a surgir con el tiempo y el niño discapacitado casi siempre se incorpora a la dinámica familiar.
\end{abstract}

\section{PALABRAS CLAVE}

Familia. Discapacidad. Historia de vida.

\section{PROPOSTA E INTENÇÕES}

Ao me propor investigar as questões vividas pelas famílias dos indivíduos em situação de deficiência, tinha a nítida percepção de que as dificuldades enfrentadas no dia a dia por tais famílias eram enormes e por demais variadas. Meus conhecimentos teóricos acerca de tal complexidade me garantiam, a priori, a amplitude das situações constrangedoras a que estão frequentemente sujeitas as pessoas em situação de deficiência e seus familiares e amigos mais próximos.

Todavia, o mundo experiencial do leitor é extremamente limitado diante da complexidade da vida real, mesmo que os autores se empenhem ardorosamente em transmitir o conteúdo de suas mensagens na maior consonância possível com a realidade. O que é passado está inevitavelmente filtrado, sendo apresentado em facetas ou em aspectos isolados que tentam, da melhor forma possível, reconstituir a totalidade dos fatos.

Não obstante a riqueza e a importância dos textos informativos, julgo ser imprescindível o contato direto com os reais sujeitos da experiência, no meu caso as mães de crianças com deficiência congênita, cujos detalhes do cotidiano são difíceis de serem transmitidos através de algumas poucas palavras escritas. 
Realizando esta pesquisa, pude vivenciar o drama de cada uma das mães entrevistadas. Suas falas, muitas vezes remissivas a fatos distantes, estavam sempre carregadas de forte emoção, como se estivessem elas reencarnando seus antigos, mas vivos, papéis de pessoas feridas, angustiadas e temerosas diante da incerteza e da falta de horizontes pessoais e sociais, tanto para elas quanto para seus filhos "desviantes".

Não pretendo, contudo, mensurar a dor de tais pessoas, posto ser permitido somente a quem sente medir a sua própria dor. Meu objetivo foi, antes de mais nada, criar um momento para que as referidas mães pudessem dizer, cada qual a seu modo, como foi e como é ter um filho que apresentou situação de deficiência no nascimento. $O$ ângulo de abordagem foi sempre o da pessoa entrevistada, o que, a meu ver, proporcionou um clima favorável ao desabafo, como se estivessem soltando um grito de suas gargantas. Daí poder afirmar hoje que a necessidade do momento não era só minha de ouvir, mas também delas de falar. Por certo, a relação estabelecida não se limitou à simples construção de dados, mas pôde, de fato, evoluir para uma relação de ajuda, em que todas cresceram, entrevistadas e entrevistadora.

Minhas idas às residências das pessoas me permitiram ir além do simples relato das histórias de vida. Pude, na verdade, conhecer o modo de vida de cada família, o tipo de relacionamento existente entre seus membros e os caminhos encontrados por cada grupo familiar para conviver com o estigma da deficiência e os respectivos esforços para o seu equacionamento.

\section{CAMINHOS METODOLÓGICOS E SUJEITOS}

Minha intenção foi utilizar a história de vida como suporte metodológico desta pesquisa, em que o discurso de cada sujeito - com sua individualidade e especificidade -, após construído, foi decomposto, reagrupado e interpretado, diluindo-se na trama social que integra o conjunto de sujeitos.

O método de história de vida ou relato de vida possibilita um dialogar com os sujeitos da pesquisa, os quais constroem as suas próprias categorias, dando condições de se ver outras dimensões e de se pensar de maneira mais criativa a problemática que, através deles, se pretende analisar. Isso implica a superação da violência implícita nos procedimentos que envolvem a imposição aos sujeitos de categorias que não Ihes dizem

Educação \& Formação, Fortaleza, v. 4, n. 12, p. 67-81 set./out. 2019

DOI: https://doi.org/10.25053/redufor.v4i12.912

http://seer.uece.br/redufor 
respeito, oriundas de uma teoria exterior a eles ou do conjunto de valores próprios do pesquisador. O que se espera, pois, é que, a partir de histórias de vida, da experiência concreta de vivências específicas, possam ser reformulados os pressupostos e as hipóteses sobre a questão em estudo.

Segundo Queiroz (1987, p. 275), a história de vida:

[...] se define como o relato de um narrador sobre sua existência através do tempo, tentando reconstituir os acontecimentos que vivenciou e transmitir a experiência que adquiriu. Narrativa linear e individual dos acontecimentos que ele considera significativos, através dela se delineiam as relações com os membros de seu grupo, de sua profissão, de sua camada social, de sua sociedade global, que cabe ao pesquisador desvendar.

O interesse do pesquisador neste tipo de pesquisa está em captar algo que ultrapassa o caráter individual do que é transmitido e que se insere nas coletividades a que pertence o narrador. As histórias de vida importam não como histórias individuais, mas na medida em que apresentam um universo social. Através dos olhos do narrador, não é ele que o pesquisador pretende ver, mas seu mundo. A história de vida capta, pois, o que se sucede na encruzilhada da vida individual com o social.

Outro aspecto importante a ser ressaltado é que, na história de vida, embora caiba ao narrador decidir o que vai narrar, compete ao pesquisador definir o tema da pesquisa e formular as questões que deseja esclarecer, propondo as questões. Dessa forma, o relato em si mesmo contém o que o sujeito da narração houve por bem oferecer. As histórias de vida também são marcadas por avanços e recuos, não devendo o pesquisador interferir para restabelecer cronologias, visto que essas variações no tempo podem constituir indícios de algo que permitirá a formulação de inferências.

Os sujeitos desta pesquisa foram seis famílias de crianças em situação de deficiência, sendo que as histórias de vida foram coletadas junto às mães de indivíduos com deficiência intelectual, deficiência visual e deficiência física, todas congênitas, detectadas no momento do nascimento, perfazendo um total de seis relatos, proporcionalmente distribuídos entre essas três categorias de deficiência.

Por questões éticas, foi resguardado o compromisso de não divulgar a identidade das famílias envolvidas nesta pesquisa, optando por nomeá-las com o primeiro nome de grandes personalidades em situação de deficiência da humanidade:

Educação \& Formação, Fortaleza, v. 4, n. 12, p. 67-81 set./out. 2019 
Cristopher $^{2}$, Loretta ${ }^{3}$, Ray $^{4}$, Helen $^{5}$, Stephen ${ }^{6}$ e Frida ${ }^{7}$. Da mesma forma, foram omitidas as citações feitas sobre nomes de instituições, ruas, bairros, cidades e profissionais que pudessem favorecer a identificação dos sujeitos da pesquisa ou comprometer a ética profissional. Os relatos foram construídos junto às mães, por estarem normalmente mais próximas de seus respectivos filhos.

Um dado importante é o fato de que trabalhei apenas com indivíduos com deficiência congênita, ou seja, aquela adquirida antes do nascimento, posto ter como questão a complexidade vivida pela família da criança em situação de deficiência que constata tal situação desde o momento de seu nascimento. Isso justifica o porquê da não inclusão na pesquisa dos casos de necessidades especiais de difícil detecção no momento do nascimento, a saber, superdotação/altas habilidades, deficiência auditiva, deficiência da fala e transtornos globais do desenvolvimento. Da mesma forma, não foram considerados os casos de deficiência múltipla com base no fato de que os mesmos, via de regra, são caracterizados, num primeiro momento, como casos de deficiência primária, normalmente a mais evidente no momento do nascimento.

Como instrumento de pesquisa, utilizou-se a entrevista, que, segundo Lüdke e André (1986), representa, ao lado da observação, um dos instrumentos básicos para a construção de dados dentro da abordagem qualitativa de pesquisa. A modalidade de entrevista utilizada foi a não estruturada, que se caracteriza pela não diretividade, favorecendo uma maior interação entre o pesquisador e o pesquisado, criando uma atmosfera de influência recíproca entre ambos. Aqui não há a imposição de uma ordem

${ }^{2}$ Christopher Joseph Burke nasceu em 26 de agosto de 1965, em Point Lookout, Nova lorque. Apresenta Síndrome de Down e é um ator estadunidense.

3 Loretta Claiborne nasceu em Nova lorque, Pensilvânia, em 1953. Apresenta deficiência intelectual e baixa visão; não andou nem falou até os 4 anos de idade. Tornou-se uma das maiores atletas da história da Special Olympics.

4 Ray Charles nasceu em 23 de setembro de 1930, em Albany, e morreu em 10 de junho de 2004, em Los Angeles. Ficou totalmente cego aos 7 anos de idade. Foi um pianista norte-americano pioneiro e cantor de música soul, blues, jazz, que ajudou a definir o seu formato ainda no fim dos anos 1950, além de um inovador intérprete de R\&B.

5 Helen Adams Keller nasceu em 27 de junho de 1880, em Tuscumbia, Alabama, e morreu em 1ํ de junho de 1968, em Westport, Connecticut. Apresentava surdo-cegueira. Foi uma escritora, conferencista e ativista social norte-americana.

${ }^{6}$ Stephen Hawking nasceu em 8 de janeiro de 1942 e morreu em 14 de março de 2018. Foi um famoso físico teórico britânico com mais de 40 anos de carreira. Tinha seu corpo comprometido por uma doença neurológica chamada Esclerose Amiotrófica Lateral.

7 Frida Kahlo nasceu na vila de Coyoacán, no México, no dia 6 de julho de 1907 e morreu em Coyoacán, no México, no dia 13 de julho de 1954. Renomada pintora mexicana que, em sua maioria, pintou retratos. Todas as suas obras são coloridas e de uma intensidade impressionante. Ela contraiu Polio quando tinha 6 anos, o que deixou sua perna esquerda bem mais fina que a direita.

Educação \& Formação, Fortaleza, v. 4, n. 12, p. 67-81 set./out. 2019

DOI: https://doi.org/10.25053/redufor.v4i12.912

http://seer.uece.br/redufor 
rígida de questões, não existindo um roteiro de entrevista. $O$ entrevistado discorre livremente a partir de referenciais temáticos propostos, definindo como quiser o campo a explorar, sem se submeter a uma estruturação predeterminada. Em termos funcionais, essa técnica possui a grande vantagem de permitir a captação imediata e corrente da informação desejada praticamente com qualquer tipo de informante. Da mesma forma, permite ainda que sejam feitas correções, esclarecimentos e adaptações durante o seu desenvolvimento, no contato direto com o sujeito pesquisado.

Aprofundando um pouco mais a questão, Thiollent (1982, p. 85) diz que:

A profundidade da entrevista permitida pela não diretividade, ligada à sua capacidade de facilitar a produção de significações fortemente carregadas de afetividade, mesmo quando se apresentam como estereótipos: o que nós procuramos pôr à luz, de fato, é a lógica subjacente às associações que, a partir da instrução inicial, irão levar o entrevistado a abordar tal ou qual tema, a voltar atrás ou progredir para outros temas.

O objetivo da entrevista não diretiva consiste em apreender as identificações através da fala dos sujeitos, mediante a superação das censuras que nela se manifestam. Isso permite a captação dos fenômenos nas suas dimensões social e individual. No intuito de ultrapassar o simples recolhimento de dados junto aos sujeitos da pesquisa, optei ainda por dar à entrevista não diretiva um caráter de entrevista de ajuda, como propõe Benjamin (1985) ao sublinhar a função de relacionamento, dando ênfase ao processo de crescimento do sujeito, paralelamente ao fornecimento de informações. Segundo Benjamin (1985, p. 14): "Ajudar, um ato de capacitação. O entrevistador capacita o entrevistado a reconhecer, sentir, saber, decidir, escolher se deve mudar. [...] A entrevista de ajuda, a ampla interação verbal entre entrevistador e entrevistado, na qual se dá o ato de capacitação".

Do ponto de vista estrutural, a entrevista, segundo esse autor, possui três momentos, que nem sempre são claramente visíveis. O primeiro momento consiste na abertura ou colocação do problema, quando é situado o assunto que motivou o encontro, encerrando quando tanto o entrevistador quanto o entrevistado compreendem o que deve ser discutido e concordam em fazê-lo. A fase de desenvolvimento ou exploração, que constitui o segundo momento, caracteriza-se pelo exame mútuo do assunto, estando o entrevistador interessado na estrutura interna de referência do entrevistado, e não naquilo que é central para si mesmo. Por fim, o terceiro momento representa 0 
encerramento, o que deve se dar mediante o conhecimento e a aceitação tanto do entrevistador quanto do entrevistado de que tal momento está ocorrendo.

Com isso, foi possível avançar na pesquisa de forma coerente e segura, sempre na intenção de aprofundar cada vez mais a problemática em estudo e tendo como referencial os relatos das histórias de vida dos sujeitos pesquisados, sem a pretensão, a priori, de confirmação ou imposição de pressupostos teóricos acerca de tal questão.

\section{REAÇÕES FAMILIARES E DEFICIÊNCIA}

Por se tratar de uma situação muito complexa e por demais problemática para a família e principalmente para a mãe, o nascimento de um filho em situação de deficiência pode desencadear uma série de comportamentos reativos, na tentativa de adaptação à situação desconfortável que normalmente se estabelece no seio da família. Muito embora haja quase tantas reações diferentes à existência de uma criança com deficiência quanto pais com tais filhos, certos tipos de reações são suficientemente comuns para justificar, por parte de diversos autores, algumas tentativas de descrição de tais comportamentos.

Telford e Sawrey (1976) destacam como reações mais frequentes à chegada de uma criança em situação de deficiência a uma família os seguintes padrões: encarar o problema de um modo realista; negação da realidade da deficiência; lamentações e comiseração dos pais com a sua própria sorte; ambivalência em relação à criança ou sua rejeição; projeção da dificuldade como causa da deficiência; sentimentos de culpa, vergonha e depressão; e padrões de mútua dependência.

Encarar os problemas da criança de modo realista - Existem pais que são capazes de enfrentar, de forma realista e bem integrada, os problemas apresentados pela presença de uma criança em situação de deficiência, da mesma forma como enfrentam as outras crises e tensões em suas vidas.

A gente tem que corrigir. Não é porque ela tem problema que eu vou deixar fazer o que ela quer, né? Porque, na minha condição de mãe, ela só tem respeito por mim aqui. (Família de Loretta).

Sobre isso não tem problema, não, minha filha. A filha é minha. [...] Eu falei com ela [a funcionária da escola]: 'A filha é minha, eu que tenho toda a obrigação de carregar ela'. Então, sempre eu vou tratando dela igual aos outros, normal. Se ela responder, precisa de coro. Não é por causa

Educação \& Formação, Fortaleza, v. 4, n. 12, p. 67-81 set./out. 2019

DOI: https://doi.org/10.25053/redufor.v4i12.912

http://seer.uece.br/redufor 
dela ser assim que ela não vai apanhar, que eu não vou zangar com ela, né? Sempre eu tenho que zangar. (Família de Frida).

Negação da deficiência da criança - A maioria dos pais reage com negação à existência de uma deficiência em um de seus filhos. Existem diversos fatores sociais e pessoais que motivam tal negação, como, por exemplo, o estereótipo cultural da criança ideal, a expectativa dos pais de que seus filhos desempenharão com êxito os papéis que a sociedade e eles próprios Ihes atribuem, as esperanças destes de que seus filhos atinjam ou ultrapassem os seus próprios empreendimentos.

Aí é que um médico disse, quando eu fui buscar ele, que ele não tinha mais nada, que estava tudo bem com ele, mas que ele tinha um problema de visão, que ele não enxergava e, por isso, não fazia as coisas. [...] $O$ pai dele, quando eu cheguei em casa e contei, me disse: 'Os médicos estão malucos. Este médico não entende de nada, você vai ver. Ele vem pra casa, nós vamos levar ele em outro médico e não vai ter nada disso'. Eu comecei a chorar e ele falou: 'Ah, que nada! Não chora, não. Isso é bobagem. Os médicos erram. Ele vai ficar bom'. (Família de Ray).

Autocomiseração - Alguns pais experimentam sentimentos de pena de si mesmos e de lamentação da sua própria sorte diante da existência de um filho em situação de deficiência.

[...] E eu me sinto muito sozinha com isso, né? Porque eu vivo pra ela e ela, assim, ela não vive pra mim, porque eu não tenho retorno nenhum. Então tem dias que eu penso: 'Puxa vida! Se a minha filha fosse uma pessoa normal, a vida da gente poderia ser tão diferente! (Família de Loretta).

Sentimentos ambivalentes em relação aos deficientes - Ao mesmo tempo que aceitam e amam os seus filhos, os pais também os rejeitam e os detestam. Esses sentimentos ambivalentes dão origem a reações de culpa, que, por sua vez, resultam em superproteção, excessiva solicitude e constante sofrimento dos pais. No que se refere ao tratamento do filho em situação de deficiência, os pais se sentem divididos entre impedir os cuidados e a assistência realisticamente necessários, por um lado, e cuidar demais, alimentando a impotência e o excesso de dependência, por outro. "O pai dele não aceitava de jeito nenhum a deficiência dele e, porque não aceitava, tratava ele cheio de dengo" (Família de Ray).

Projeção - Ocorre quando os pais, ao tentarem se defender contra a própria ansiedade, responsabilizam os outros pelo desconforto causado pela deficiência do filho. 
Os pais angustiados projetam frequentemente as causas da deficiência da criança nos outros filhos, no cônjuge, no médico, no professor, no psicólogo ou mesmo na sociedade em geral. "Inclusive porque o pai me acusava [...], porque aí ele me acusava e eu acusava ele" (Família de Loretta).

Culpa, vergonha e depressão - A vergonha é mais alterorientada, envolvendo a expectativa de ridículo ou crítica de outros. Já a culpa é mais ego-orientada, implicando a autocensura, o remorso e um sentimento de depreciação pessoal. Ambos os sentimentos implicam um alto grau de ansiedade. A depressão surge da associação do sentimento de culpa ou de autorrecriminação com a ansiedade e a depreciação pessoal. Por outro lado, a associação da vergonha e da ansiedade pode proteger o conceito de eu, dirigindo a hostilidade para o exterior.

Eu tive uma preocupação muito grande com a causa do problema, porque, antes deu ficar grávida dela, eu fazia uso de drogas, sabe? Então, eu achei, assim, que podia ser alguma consequência. [...] Então, o meu medo, quando a menina nasceu, foi isso [...]: eu tive sensação de culpa na hora. (Família de Loretta).

Padrões de dependência mútua - Normalmente a criança em situação de deficiência mantém uma relação de dependência com seus pais. Alguns pais, no entanto, também se tornam dependentes da criança em situação de deficiência. Isso ocorre quando um dos pais (ou ambos) investe uma grande parte de si mesmo na assistência ao filho em situação de deficiência. Retroalimentada, essa dependência mútua pode se perpetuar, constituindo-se numa relação neurótica.

Eu conheço; tem uma irmã de um amigo que está em cima de uma cama. Nunca andou. Está com 38 anos. A mãe dela é um caco, um caquinho, mas um caquinho mesmo, sabe? Mas está viva, cuidando dela até hoje. E ele sempre fala: 'Mãe, a hora que a senhora morrer, a fulana morre. A hora que a fulana morrer, a senhora morre, né?'. A ligação é muita. É como, eu te falei. A minha filha não dorme se eu não estiver; não dorme, não come; ela não aceita outra pessoa dando comida. Come, assim, ela faz uma bagunça, não fica sentada na mesa, sabe? Então, assim, vai ser muito difícil, né? Vai ser muito difícil mesmo. (Família de Loretta).

Preocupados em descrever as possíveis reações dos pais de crianças em situação de deficiência, Telford e Sawrey (1976) não estabeleceram qualquer ligação entre as mesmas, abordando-as de forma independente e sem uma visão dinâmica em termos de fases ou passos de um processo maior de conflito e tentativa de superação da

Educação \& Formação, Fortaleza, v. 4, n. 12, p. 67-81 set./out. 2019

DOI: https://doi.org/10.25053/redufor.v4i12.912

http://seer.uece.br/redufor 
crise instaurada pelo nascimento de um concepto malformado. Ao contrário, Moura (s.d.) sistematiza em fases a passagem pelo processo de elaboração dos conflitos advindos desta crise.

1ำ fase: Negação - A negação da realidade surge como uma tentativa de se criar um escudo protetor contra a dor intensa advinda do choque inicial. Essa negação pode se manifestar também sob a forma de indiferença, apatia ou negação maníaca, com preocupações supérfluas, sob a forma de movimentação e falas exageradas.

Foi uma luta de sobrevivência. Esse período nem conta, não lemos nada, não tivemos informação. Era só problema cardíaco. Retardo... não tinha retardo. Não tinha noção das características Down, nada, não enxergava, não via. Não me interessava, porque era aqui e agora, e já era. (Família de Cristopher).

Eu cheguei em casa, depois de uma semana, mais ou menos. Eu falei com meu marido assim: 'Essa menina não enxerga'. Ele quase morreu. Caiu pra trás, falou: 'Você tá ficando doida? Deus me livre! Que não enxerga o quê?'. [...] Ele falou: 'Nossa Senhora! Deus me livre! Você tá ficando maluca'. (Família de Helen).

2a fase: Liberação de reações impulsivas - Passada a primeira fase, há uma liberação de reações impulsivas que se traduzem em sentimentos de decepção, raiva, tristeza e frequentemente desejo de que a criança morra. Dificilmente são aceitas, neste momento, as sugestões de solução, porque a emoção está muito intensa, ocupando todo o espaço do racional. "Mas, quando tive ele, eu tive muita decepção" (Família de Ray).

3를 fase: Busca do culpado - Diante da não aceitação do filho em situação de deficiência e do sentimento de culpa subjacente à rejeição, surge a necessidade de se buscar o culpado - o parceiro, o médico, a ascendência familiar de cada um, etc. - para aliviar a angústia. "Igual a minha cunhada... a irmã dele... às vezes, fala com ele pra ele fazer exame de sangue, que, às vezes, nosso sangue não combina" (Família de Frida).

$4^{a}$ fase: Depressão - Com o tempo, a realidade se impõe. Instala-se, pois, uma profunda tristeza, cuja expressão vai permitir que o luto seja vivido, os sonhos enterrados e outros sentimentos possam agora aflorar.

Às vezes, o dia que eu estou, assim, angustiada, deprimida, que eu exponho pra eles [os amigos] o meu problema, eles dizem: 'Não, a menina é o seu arrimo. Às vezes, se não fosse ela, você poderia estar numa pior'. Então aquilo, assim, me conforta durante um tempo, né? (Família de Loretta).

Educação \& Formação, Fortaleza, v. 4, n. 12, p. 67-81 set./out. 2019

DOI: https://doi.org/10.25053/redufor.v4i12.912 
5aㅗ fase: Aceitação - A aceitação ocorre quando a família encontra um significado para aquele filho em sua vida.

Outro fato importante, segundo Moura (s.d.), é que pode ocorrer a cristalização numa das fases do processo, instalando-se, assim, um quadro patológico. Dentre outras situações, pode ocorrer a separação do casal, ou então a família pode se estruturar em torno da criança em situação de deficiência, que vai ser o depositário da doença de todos. "Porque tem caso de pediatra no Rio que abandonou, nunca mais voltou em casa, quando assistiu o parto e viu que era Down, não voltou, outros... e um monte de casos, né?' (Família de Cristopher).

Farber (apud SILVA, 1988) admite dois tipos de crise quando a deficiência do filho é percebida pelos pais como um evento incontrolável: crise trágica, que ocorre quando os pais percebem que não poderão realizar todos os seus sonhos e expectativas em relação à criança, e crise da desorganização de papéis, que implica uma perturbação no ciclo de vida familiar.

Esse mesmo autor denomina como adaptação o processo de ajuste à condição geradora dessa crise. Esse fenômeno se dá através de modificações dos papéis e normas de cada um dos membros da família ou da interação familiar que os mesmos empreendem, individual ou coletivamente, para lidar efetivamente com a situação-problema, seja para solucioná-la ou mesmo para conseguir conviver com ela.

Conforme Wolfensberger (apud SILVA, 1988), podem ocorrer três tipos de crise subsequentemente ao momento da descoberta da deficiência da criança: crise da chocante novidade, que se instala quando os pais são surpreendidos pela chegada do filho em situação de deficiência, acarretando a frustração das expectativas que eles alimentavam sobre o futuro do mesmo. "Então, passou essa fase assim meia do silêncio, do susto, né? Que a gente passou aquela coisa assim meio obscurecida realmente" (Família de Cristopher); "Se a gente fosse preparado... era melhor de aceitar" (Família de Stephen).

Crise de valores pessoais, que consiste nas reações dos pais diante da deficiência da criança e das manifestações dessa deficiência, que são inaceitáveis na sua escala de valores. "Quando ele [o pai] vinha buscar as crianças pra passear só queria levar a menina, e eu mandava levar o menino também" (Família de Stephen).

Crise da realidade, que decorre das circunstâncias que exigem dos pais cuidados constantes que ultrapassam as suas capacidades pessoais, tais como os cuidados físicos 
intensivos exigidos pela criança, hiperatividade ou algum comportamento perigoso dela que tornam exaustiva a convivência diária com essa criança.

\begin{abstract}
Porque eu não tenho vergonha dela, você entendeu? Às vezes, eu fico brava com ela, mas eu saio com ela de manhã pra ir pro colégio, ela faz xixi na roupa, eu fico brava com ela e tudo, mas não é assim de vergonha. É porque não tá em mim, né? Com dez anos, assim, e eu lutando com ela. [...] Mas eu sinto falta, assim, porque ela não sabe falar, né? Então, às vezes, o dia que eu estou brava, eu falo assim: 'É, eu não sou mãe, eu sou uma babaca, né?'. Então, tem aqueles dias em que a gente cai na real mesmo. Não assim que eu tente tapar o sol com a peneira, não é isso, não, mas tem aqueles dias assim em que a gente tá mais frágil, mais sensível, né? (Família de Loretta).
\end{abstract}

Desde pequena eu fui ensinando tudo. Ah, mas o trabalho é dobrado, porque vai muito da mãe, sem dúvida. O trabalho que dá uma criança deficiente. Nossa Senhora! É triste! Não é igual ao trabalho de uma criança normal. (Família de Helen).

Antes ela evacuava sete vezes por dia. Você acabava de trocar a roupa dela, quando você ia lá pra cozinha, tá ela lá: 'Deixa a mãe ver'. 'Nada não, mãe. Não tem nada, não'. Ela tinha medo de contar, né? Até 8, 9 anos por aí, ela fazia. Olhava: 'Ah, meu Deus! Tá essa menina suja de novo'. Às vezes, época de frio, não tinha uma calça comprida pra pôr nela. Pegava ela... ficava nervosa com ela... dava banho... gritava com ela... punha ela lá e voltava. (Família de Frida).

Com base na sua experiência de muitos anos de acompanhamento de mais de 350 crianças com Síndrome de Down e respectivos familiares, Lefèvre (1985) observou que o nascimento de uma criança em situação de deficiência desperta diversas reações em seus familiares. Nos primeiros dias, ocorre a descrença. Ao longo dos primeiros meses, verificam-se a confusão, a incerteza e até a hostilidade para com o mundo. Com o tempo, surge uma esperança e se desenvolve o interesse pela criança. À medida que a criança começa a falar, andar e aprender a fazer algumas coisas sozinha, vai surgindo uma certa tranquilidade em relação ao problema. Todavia, diante da surpresa e/ou insegurança que aparecem quando novos problemas se delineiam, podem advir a agressividade e/ou teimosia.

Para Martins (apud SILVA, 1988), o nascimento de uma criança em situação de deficiência quase sempre leva os pais ao trauma emocional, fazendo com que cheguem ao desespero, com acusações mútuas de culpa e de hereditariedade, o que não Ihes permite um raciocínio lógico para enfrentarem o problema e lutarem pela recuperação da criança.

Educação \& Formação, Fortaleza, v. 4, n. 12, p. 67-81 set./out. 2019

DOI: https://doi.org/10.25053/redufor.v4i12.912

http://seer.uece.br/redufor 
Todas essas possíveis reações desencadeadas pelo nascimento de um filho em situação de deficiência são relativizadas pelas experiências anteriores do casal e pelas concepções de homem e de vida que o mesmo tenha naquele momento. De qualquer modo, a superação do sofrimento culmina sempre numa atitude de incorporação da deficiência da criança à dinâmica familiar. Segundo Silva (1988), o casal pode desenvolver dois comportamentos distintos: aceitar ou assumir a deficiência imposta. Para ela, aceitar implica o fato de a pessoa não se sentir mais infeliz, diminuída ou diferente por possuir uma criança em situação de deficiência, não mais se revoltar na busca da causa da deficiência do filho e não ter raiva das pessoas normais ou que têm filhos normais. Assumir, por sua vez, implica a tomada de decisão de se fazer o que for necessário para abordar o problema da criança. Todavia, o assumir não redunda na parcial ou total aceitação do problema e/ou da criança afetada. Ressalta Silva (1988) que o que comumente é chamado de aceitação é, na verdade, o assumir o problema. Isto é, os pais deixam de ter "pensamentos mágicos" e passam a enfrentar os problemas associados à deficiência do filho de forma refletida e realística, buscando recursos e/ou tratamentos e participando das estratégias de intervenção junto à criança.

Importa frisar que, ao aceitar ou assumir a deficiência do filho, os pais estão se colocando numa posição de enfrentamento do problema, ao mesmo tempo que evitam as atitudes de rejeição ou superproteção da criança. Caso contrário, os pais tornam-se agentes inadequados para o atendimento da criança em situação de deficiência, o que expõe ainda mais a criança a uma reduzida estimulação, acarretando-lhe um desenvolvimento ainda mais defasado.

\section{QUESTÕES E POSSIBILIDADES}

Importa ressaltar ainda que as reações trabalhadas nesta pesquisa não são, em nenhuma hipótese, exclusivas das mães de crianças em situação de deficiência. Mesmo as mães de filhos "normais" vivem a ansiedade do momento do parto, desenvolvem reações diversas ao filho real, preocupam-se com seu futuro educacional, profissional e afetivo, sofrem e alegram-se com seus sucessos e fracassos. Todavia, todas essas situações naturais podem ser, e certamente o são, agravadas com a inclusão de um dado novo: o desvio acentuado de seu filho da curva de normalidade socialmente concebida e aceita. 
Por fugir dos sonhos da família e em especial dos sonhos da mãe, o filho real provoca uma grande reviravolta nos planos iniciais de todos que o esperavam. A partir da constatação da deficiência, surgem os questionamentos e a busca de possíveis soluções. Das ruínas dos sonhos desmoronados deve surgir o alicerce da nova família, mesmo que nesta busca estejam presentes as ideias e os sentimentos de morte (MANNONI, 1988).

Negar, rejeitar, buscar um culpado para a situação, refugiar-se no seu sofrimento (que lhe parece o maior de todos) são algumas reações perfeitamente possíveis nos pais de crianças em situação de deficiência. Entretanto, a busca do equilíbrio e 0 encaminhamento das questões afetas ao ser desviante tendem a surgir com o tempo e o filho em situação de deficiência é quase sempre incorporado à dinâmica familiar, fortemente influenciada pela nova situação. Contudo, existe a possibilidade de a família não conseguir se reestruturar, podendo se instaurar um quadro patológico mais sério, em que a deficiência do filho alimentaria direta e/ou indiretamente a doença dos demais membros do grupo familiar.

É de fundamental importância que se busque diminuir o impacto da notícia do nascimento de um filho em situação de deficiência, através de uma adequada intervenção dos médicos, enfermeiros e psicólogos junto aos pais, formulando diagnósticos e prognósticos claros, ressaltando as possibilidades do filho e respeitando, acima de tudo, o sofrimento e a angústia presentes no casal e em especial na mãe da criança. Para cumprir todo o processo de luto, é necessário que os pais se entreguem à experiência de todas as suas emoções, precisando de pessoas que thes permitam que 0 luto aconteça e os reconheçam como pessoas, e não simplesmente como pais de uma criança em situação de deficiência.

Uma importante fonte de apoio aos pais de pessoas em situação de deficiência é o relacionamento com outros pais que vivenciam a mesma situação. Daí a necessidade de se criar espaços propícios para tal atividade, de modo que as experiências de uns sirvam de aprendizado para os outros.

Outra medida que se faz urgente é a difusão das informações teóricas e práticas acerca da problemática vivida pelas pessoas em situação de deficiência na nossa sociedade. Por certo, o caminho mais seguro e tranquilo seria a inclusão imediata de disciplinas específicas nas grades curriculares de todos os cursos e em todos os graus de ensino. Este seria, sem dúvida, o primeiro e decisivo passo para uma mudança na 
mentalidade e nas atitudes das pessoas em relação à aceitação e ao respeito para com o outro em situação de deficiência. Todas essas medidas, no conjunto, visam atacar 0 grande e principal problema enfrentado pelas pessoas em situação de deficiência: a segregação social.

\section{REFERÊNCIAS}

BENJAMIN, A. A entrevista de ajuda. 3. ed. São Paulo: Martins Fontes, 1985.

LEFÈVRE, B. H. Mongolismo: orientação para famílias. 2. ed. São Paulo: Almed, 1985.

LÜDKE, M.; ANDRÉ, M. E. D. A. Pesquisa em educação: abordagens qualitativas. São Paulo: EPU, 1986.

MANNONI, M. A criança retardada e a mãe. 2. ed. São Paulo: Martins Fontes, 1988.

MOURA, M. D. Nascimento do concepto mal-formado: aspectos psicológicos. Belo Horizonte: Hospital Mater Dei, s.d. (Mimeo).

MARQUES, L. P. Em busca da compreensão da problemática da família do excepcional. 1992. Dissertação (Mestrado em Educação) - Programa de Pós-Graduação em Educação, Pontifícia Universidade Católica do Rio de Janeiro, Rio de Janeiro, 1992.

QUEIROZ, M. I. P. Relatos orais: do "indizível" ao "dizível". Ciência e Cultura, São Paulo, v. 39, n. 3, p. 272-286, 1987.

SILVA, S. F. Experiências e necessidades de mães após o diagnóstico de deficiência mental do filho. Dissertação de Mestrado. São Carlos: UFSCar, 1988.

TELFORD, C.; SAWREY, J. M. O indivíduo excepcional. 2. ed. Rio de Janeiro: Zahar, 1976.

THIOLLENT, M. Crítica metodológica, investigação social e enquete operária. São Paulo: Polis, 1982.

Luciana Pacheco Marques (Brasil, Minas Gerais, Juiz de Fora) Universidade Federal de Juiz de Fora (UFJF)

Doutora em Educação pela Universidade Estadual de Campinas (Unicamp). Professora da UFJF. Lattes: <http://lattes.cnpq.br/5969492483399686>.

E-mail: <luciana.marques65@gmail.com>.

Recebido em 28 de janeiro de 2019.

Aceito em 14 de maio de 2019.

Educação \& Formação, Fortaleza, v. 4, n. 12, p. 67-81 set./out. 2019

DOI: https://doi.org/10.25053/redufor.v4i12.912

http://seer.uece.br/redufor 